\title{
p53 deficiency resulted in enhanced IGF-1R signaling pathway inhibition by metformin in lung adenocarcinoma cells
}

\author{
Wei Dong ${ }^{1}$, Yunxia Zhao ${ }^{2}$, Hongxin $\mathrm{Cao}^{3}$, Zhinan $\mathrm{Wu}^{1}$ and Jiajun $\mathrm{Du}^{1}$ \\ ${ }^{1}$ Department of Thoracic Surgery, Shandong Provincial Hospital Affiliated to Shandong University, Jinan, China \\ ${ }^{2}$ Department of Neurology, Shandong Provincial Hospital Affiliated to Shandong University, Jinan, China \\ ${ }^{3}$ Department of Oncology, Shandong University Qilu Hospital, Shandong University, Jinan, China \\ Correspondence to: Jiajun Du, email: dujiajun@sdu.edu.cn \\ Wei Dong, email: dongwei318@163.com \\ Keywords: metformin, insulin like growth factor receptor subtype 1 (IGF-1R), p53, anticancer therapy, lung adenocarcinoma cells \\ Received: April 28, $2017 \quad$ Accepted: September 20,2017 Published: October 06, 2017 \\ Copyright: Dong et al. This is an open-access article distributed under the terms of the Creative Commons Attribution License 3.0 \\ (CC BY 3.0), which permits unrestricted use, distribution, and reproduction in any medium, provided the original author and source \\ are credited.
}

\section{ABSTRACT}

Research in recent years revealed that the antidiabetic drug metformin has some anticancer properties, and p53 plays an important role in the metformin-induced tumor inhibition. But less clear is the mechanism by which p53 status affects metformin mediated cancer cell responses. In this study, the effect of metformin on cancer cells with different p53 genotypes was investigated, and we found metformin could inhibit cancer cell proliferation especially in p53-deficient cells. So a paired isogenic nonsmall cell lung cancer cell lines H1299 $\mathrm{p53}^{+/+}$and H1299 p53/- was involved to explore the possible mechanisms. We detected the differences in cell proliferation and solid tumor formation induced by metformin, furthermore, the signaling transduction of insulin like growth factor-1 receptor (IGF-1R) was evaluated, which was essential in cancer transformation and progression. Our results indicated that p53 deficiency lead to more efficient inhibition of IGF-1R signaling transduction, receptor degradation and ubiquitination induced by metformin, which resulted in enhanced cell apoptosis and proliferation inhibition in vitro, and more significant solid tumor growth retardation and cancer cell death in vivo. Although more cell lines and multiple experiments were required to make a general conclusion, our study suggested the enhanced inhibition of IGF-1R signaling pathway contribute to the metformin's selective toxicity in p53deficient lung adenocarcinoma cells.

\section{INTRODUCTION}

The biguanide metformin is the most widely used treatment drug for type 2 diabetes. It is believed to exert its effect by reducing hepatic glucose production and increasing insulin sensitivity as well as glucose use by peripheral tissues [1]. Recent studies showed encouraging findings that metformin could reduce cancer risk or improve cancer prognosis both in vitro and in vivo [2]. Two types of distinct but not exclusive anticancer effect were concluded: first, by decreasing insulinemia and glycaemia, metformin could block PI3K/MAPK signaling pathway implicated in cell growth; second, through the activation of the AMPK pathway, metformin could directly act on cancer cells by targeting various pathways including tumor metabolism, inflammation, angiogenesis and cancer stem cells [3]. The AMPK pathway was agreed to play the major part in the anticancer mechanisms of metformin.

The TP53 tumor suppressor gene is one of the most frequently $(>50 \%)$ mutated genes in lung cancer [4], which has also been associated with poor progress and therapy resistance [5]. Generally, functional p53 was crucial in the regulation of cell cycle, apoptosis and senescence in response to DNA damage, hypoxia, and oncogenic activation [6]. Also as an important regulator of cancer cell metabolism [7], the loss of p53 in cancer cells might be a main force behind the acquisition of glycolytic phenotype [8], lead to the abnormality in cancer cell glucose metabolism. Recent reports have revealed 
that p53 plays an important role in the metformininduced inhibition of proliferation and AMPK activation $[3,9,10]$. And data from present study demonstrated p53 knockdown or mutation has a negative effect on metformin-induced growth inhibition, senescence and apoptosis [11]. However, the possible mechanism by which p53 status influenced metformin mediated cellular responses is still an important question to be addressed.

The insulin like growth factor-1 receptor (IGF-1R) is an important upstream regulator of AMPK pathway [12], and IGF-1R signaling plays a critical role in cancer transformation and progression [13]. Overexpression of IGF-1R is observed in wide range of human cancers including lung cancer, and it is becoming one of the most intensively investigated molecular targets in oncology [14]. Recently, there are researches on the emerging effects of metformin on IGF-1R system. In our previous studies, we found metformin could inhibit IGF-1R signaling pathway and have synergistic effects with IGF$1 \mathrm{R}$ antibody in both small cell and non-small cell lung cancer cell lines $[15,16]$. And similar regulation effect of metformin on IGF signaling was found in endometrial cancer cells [17].

In this study, the proliferation inhibition of metformin on cancer cells with different p53 genotypes was investigated, and a paired isogenic cell lines H1299 $\mathrm{p} 53^{+/+}$and H1299 $\mathrm{p} 53^{-/-}$was involved to explore the difference caused by p53 deficiency in vitro and in vivo. Moreover, we detected the changes in IGF-1R signaling pathway to explore the possible mechanisms of p53 status in metformin-induced antitumor effects.

\section{RESULTS}

\section{Metformin-induced proliferation inhibition in cancer cells with different p53 status}

The p53 expression and transcription level in five different non-small cell lung cancer cell lines were checked by WB and RT-PCR. In accordance with previous researches, p53 protein and mRNA was detected in A549 and H460 cells (p53 wild type), but not in H520, H1975 (mutant type) and H1299 (deleted type). The cell viability and IC50 of metformin were detected by PrestoBlue Cell Viability Assay, and we found that the p53 mutant and deleted type cancer cells (H520, H1975 and H1299) were less resistance to metformin induced antitumor effects, with statistically significant lower metformin half maximal inhibitory concentration (IC50) and cell viability curves (Figure 1A\&1B). Then flow cytometry was performed to evaluate the metformin induced apoptosis of cancer cells with different p53 status, and we found both the early and late cell apoptosis of p53 mutant and deleted type cancer cells were significantly increased than p53 wild type cancer cells (Figure 1C).

\section{Cancer cell proliferation and apoptosis of H1299 $\mathrm{p53}^{+/+}$and $\mathrm{H} 1299 \mathrm{p53}^{-/-}$}

Since cancer cells with different p53 status showed significant difference in the treatment reaction

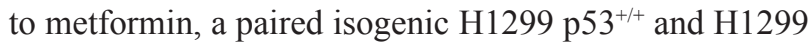
$\mathrm{p} 53^{-/}$was enlisted in further experiment to confirm the difference caused by p53 deficiency and to explore the possible mechanism.

The cell viability and apoptosis experiments were repeated with new cell lines, and once again, metformin significantly inhibit cancer cells proliferation especially in p53-deficient cells, more significant reduction in cell growth and increased cell death was detected, and dosedependent inhibition was shown in Figure 2.

\section{Solid tumor formation and cancer cell apoptosis}

In order to investigate the possible changes in tumor formation ability of cancer cells with different p53 status, we subcutaneously transplanted H1299 $\mathrm{p} 53^{+/+}$and $\mathrm{p} 53^{-/-}$ cells in BALB/c-nu mice, and the inhibition of solid tumor formation by metformin was detected. The tumor growth in size and weight was recorded and cancer cell apoptosis was evaluated. We found that metformin could significantly inhibit solid tumor growth and induce more cancer cell apoptosis in both $\mathrm{H} 1299 \mathrm{p} 53^{+/+}$and p53 $3^{-/-}$cells compared to control groups, however, more significant retardation of tumor development and cancer cell death was found in the tumor model of p53-deficient cells (Figure 3).

\section{IGF-1R tyrosine phosphorylation and signaling transduction}

To explore the possible mechanism by which p53 status affect the antitumor reactions induced by metformin, we investigated the difference of $\mathrm{H} 1299 \mathrm{p} 53^{+/+}$ and $\mathrm{p} 53^{-/}$cells in IGF-1R signaling pathway. Following serum starvation for $12 \mathrm{~h}, \mathrm{H} 1299{\mathrm{p} 53^{+/+}}^{-1}$ and $\mathrm{p}^{-/-}$cell lines were treated with $50 \mathrm{ng} / \mathrm{ml} \mathrm{IGF-1} \mathrm{or} \mathrm{first} \mathrm{treated}$ with $3 \mathrm{mM}$ metformin for $30 \mathrm{~min}$ and then stimulated with $50 \mathrm{ng} / \mathrm{ml} \mathrm{IGF-1} \mathrm{for} \mathrm{2,} \mathrm{5,} \mathrm{10,} 30$ and $60 \mathrm{~min}$. As seen in Figure 4, metformin could significantly decrease the IGF-1 (the IGF-1R ligand) induced IGF-1R tyrosine phosphorylation in both the two cell lines. And also the IGF-1 induced Akt and ERK activation was significantly inhibit, which are the two main proteins of IGF-1R signaling transduction. Moreover, there was significant difference in both IGF-1R phosphorylation and signaling transduction between the two cell lines with or without p53 deficiency (Figure 4C). It could be concluded that metformin could more efficiently inhibit IGF-1R tyrosine phosphorylation and signaling transduction in p53deficient cancer cells. 


\section{IGF-1R degradation and ubiquitination}

Receptor degradation and ubiquitination both were important biological behaviors, and could determine the receptor activity to some extent. To detect the IGF-1R degradation, H1299 $\mathrm{p} 53^{+/+}$and $\mathrm{p} 53^{-/-}$cells were treated with $100 \mathrm{ng} / \mathrm{ml}$ IGF-1 or $5 \mathrm{mM}$ metformin in serum free medium for $0,6,12$, and $24 \mathrm{~h}$. We found that metformin significantly down-regulated the IGF-1R expression as the ligand IGF-1 (Figure 5). For the ubiquitination, cells were treated with $100 \mathrm{ng} / \mathrm{ml} \mathrm{IGF-1} \mathrm{or} 5 \mathrm{mM}$ metformin for $10 \mathrm{~min}$ after $24 \mathrm{~h}$ serum starvation, and then immunoprecipitation and immunoblotting as above. The results indicated that metformin could induce the IGF-1R ubiquitination after 10 min stimulation in both the two cell lines. Moreover, ubiquitination induced by metformin was much stronger in $\mathrm{H} 1299 \mathrm{p} 53^{-\digamma}$ cells, which indicated metformin-mediate IGF-1R ubiquitination was enhanced in the absent of $\mathrm{p} 53$ protein.

\section{DISCUSSION}

Metformin has recently received increased attention for its potential antitumor effects in clinical and experimental studies. The anticarcinogenic effects of metformin have been attributed including activation of AMPK pathway, induction of cell cycle arrest and/
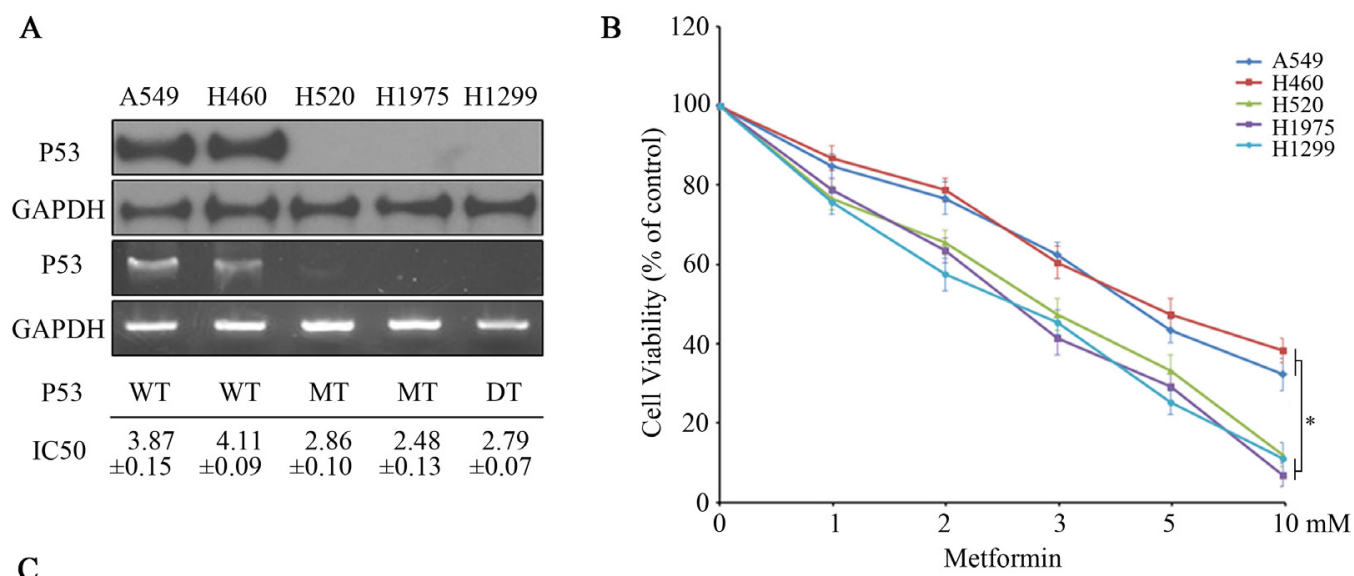

C
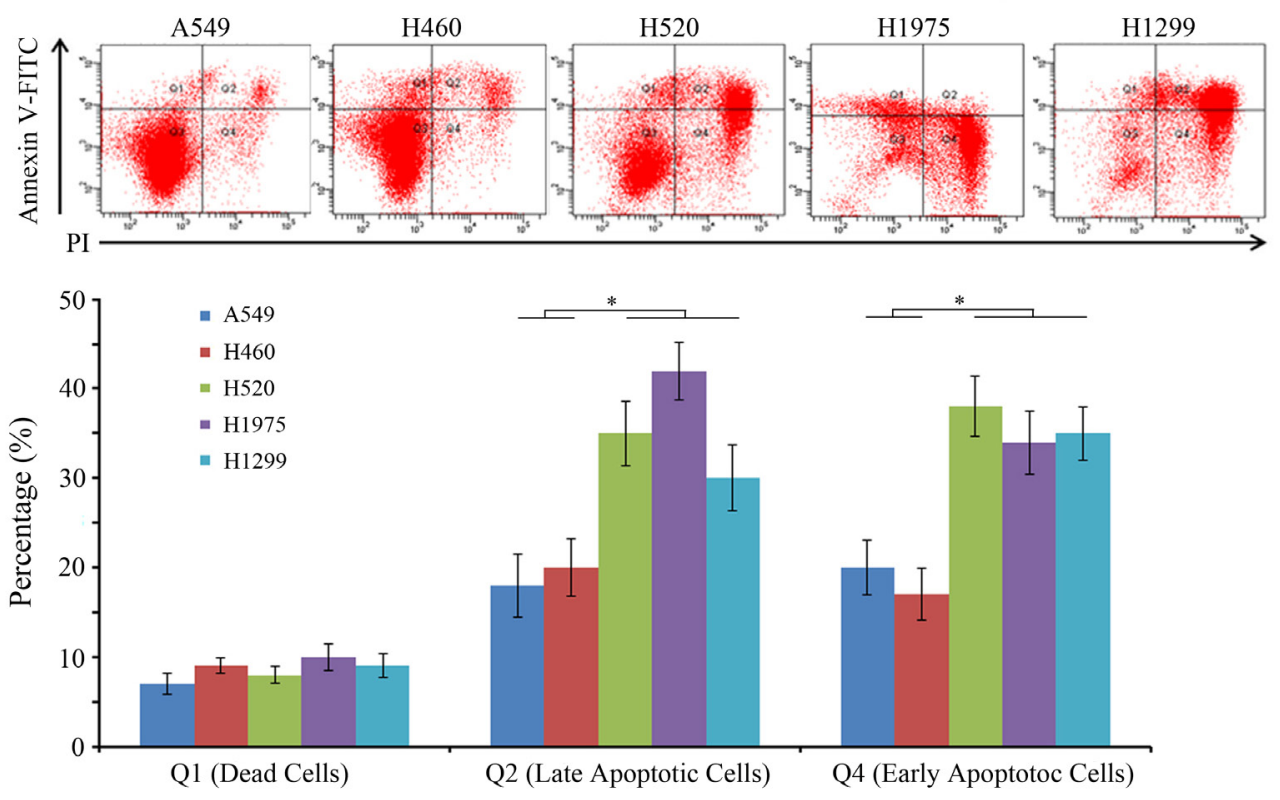

Figure 1: Metformin induced proliferation inhibition in non-small cell lung cancer cell lines. (A) Five different non-small cell lung cancer cells A549, H460, H520, H1975 and H1299 were detected by WB and RT-PCR for p53 expression and transcription, and metformin half maximal inhibitory concentration (IC50) for all cell lines was quantified as listed. (B) Cells were treated with Metformin of different concentration for $24 \mathrm{~h}$ and cell viability was measured by PrestoBlue Cell Viability Assay. The number of viable cells following Metformin treatment was presented as percentage of untreated cells. Data were presented as mean \pm S.E.M. (C) Cells were cultured in 6 well plates and $3 \mathrm{mM}$ metformin was added to the wells for $24 \mathrm{~h}$. After that cells were collected in tubes and treated in accordance with Annexin V-FITC/PI apoptosis detection kit. The percentage of cells labeled as Annexin V (+) PI (-), Annexin V (+) PI (+) and Annexin V (-) PI (+) was investigated. Overall, there were significant differences between p53 wild type cells (A549 and H460) and p53 mutant/ deleted type cells (H520, H1975 and H1299) in either cell viability or early/late cell apoptosis ( $\left.{ }^{*} \mathrm{P}<0.05\right)$. 
or apoptosis, inhibition of protein synthesis, reduction in circulating insulin levels, inhibition of the unfolded protein response (UPR), activation of the immune system, and eradication of cancer stem cell (well reviewed in [1, $3,18]$ ). Besides these, in our study we found metformin could inhibit phosphorylation of IGF-1R and downstream Akt and ERK signaling, induce significant IGF-1R degradation and ubiquitination, which lead to cancer cell proliferation inhibition in vitro and solid tumor growth retardation in vivo. Moreover, we found p53 played an important role in these metformin induced IGF-1R dependent tumor suppression.
Recent studies have revealed the undeniable fact that most human cancers display enhanced IGF-1R concentrations and express high IGF-1R mRNA levels $[19,20]$. IGF-1R activation initiates downstream cascades which are essential in cancer cell metabolism, mainly including phosphatidylinsitol-3-Kinase (PI3K), Akt and mTOR; and Ras, Raf and MAPK/ERK [21]. Activation of these pathways led to oncogenic transformation, proliferation and survival of cancer cells [22]. In our study, we found metformin could significantly inhibit IGF1 (the ligand) induced IGF-1R activation and signaling transduction, and the downstream Akt and ERK activation
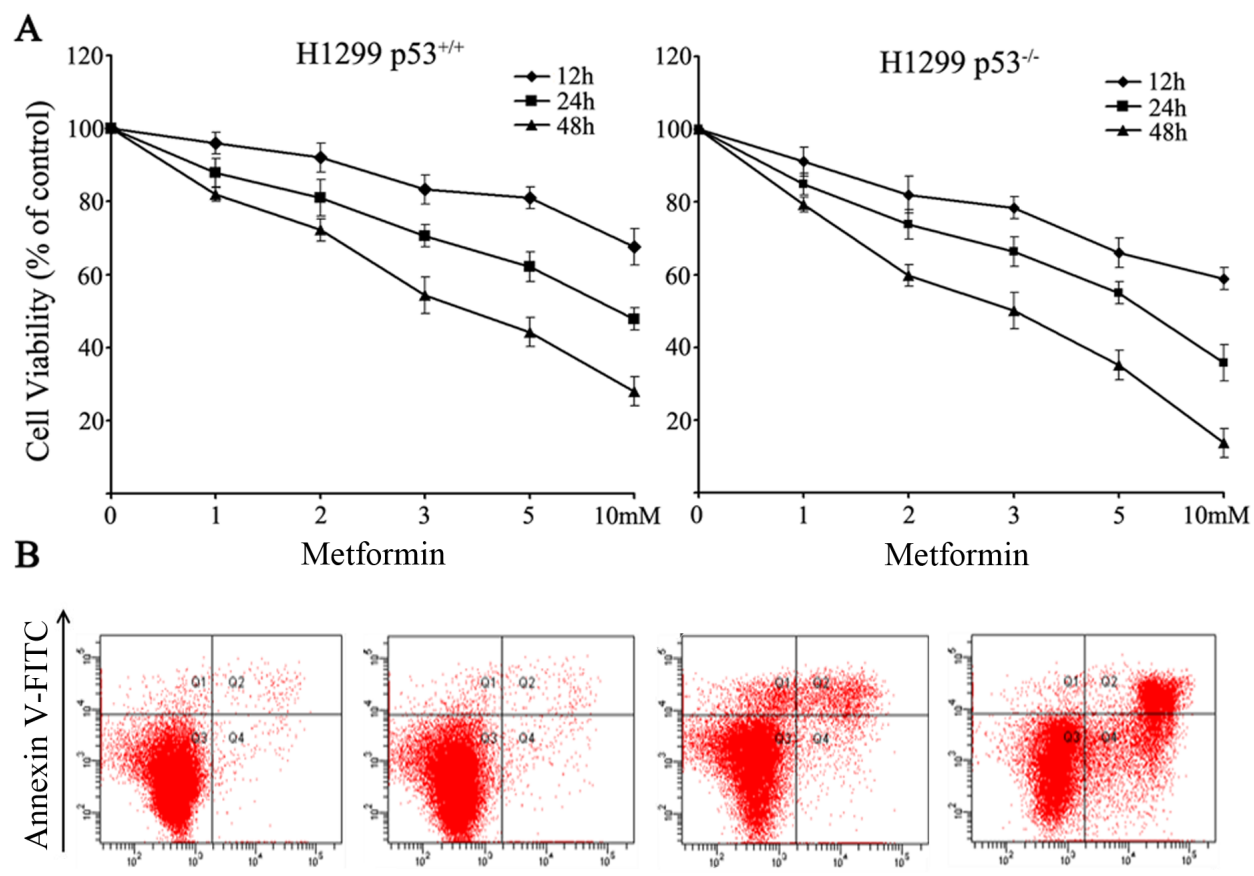

\section{PI}

$\mathrm{H} 1299 \mathrm{p} 53^{+/+}$

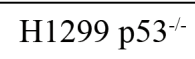

$\mathrm{H} 1299 \mathrm{p} 53^{+/+}$Met

$\mathrm{H} 1299 \mathrm{p} 53^{-/-} \mathrm{Met}$

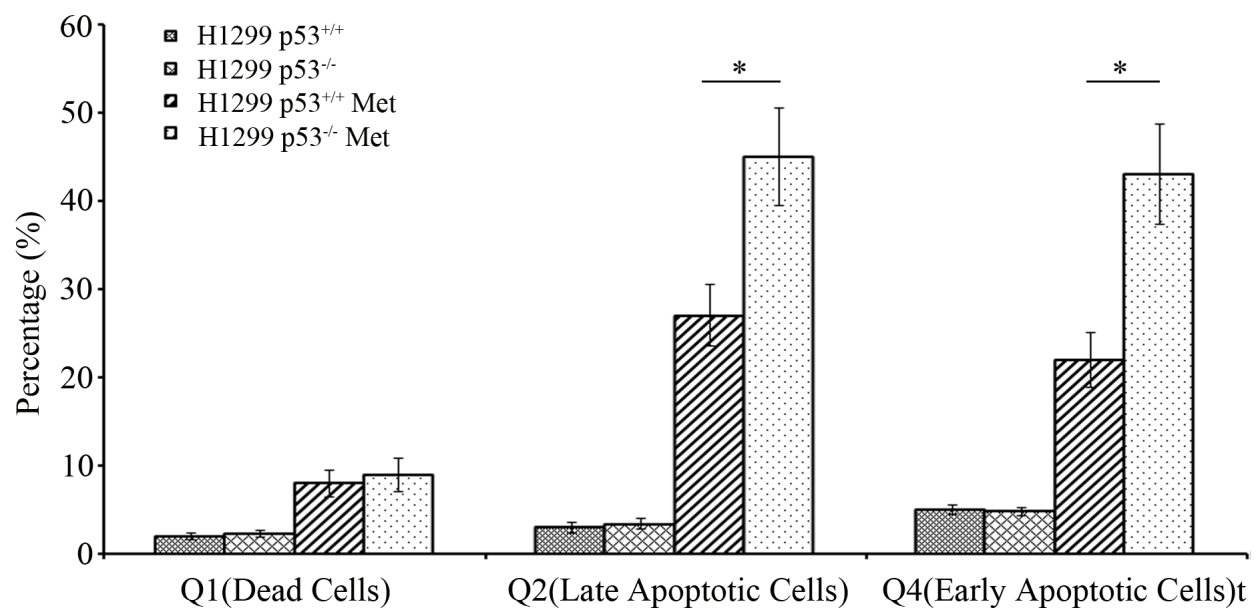

Figure 2: Difference in proliferation inhibition and apoptosis of $\mathrm{H}_{1299} \mathrm{p53}^{+/+}$and $\mathrm{H1299} \mathrm{p53}^{-/-}$induced by metformin. (A) Cells were treated with Metformin of different concentration for 12, 24, and $48 \mathrm{~h}$. Cell viability was measured and data were shown in cell viability curves with mean \pm S.E.M. (B) Cells were treated with $3 \mathrm{mM}$ Metformin for $24 \mathrm{~h}$ and then flow cytometry was performed to detect the cell apoptosis. There was significant difference between cancer cells with different p53 status in either cell viability or early/late cell apoptosis $\left({ }^{*} \mathrm{P}<0.05\right)$. 
was believed to mediate AMPK inhibition. In another word, metformin induced IGF-1R signaling inhibition also paved the way to metformin induced AMPK activation, this feedback loop might be a good supplement for the anticarcinogenic effects of metformin as listed above.

In addition to its role in cell growth-inducing activities, IGF-1R was reported to have important function in metabolic regulation [23]. The PI3K pathway, which is activated following IGF-1R activation, not only provides antiapoptotic and mitogenic signals but also has significant effect on cancer cell metabolism. The downstream proteins of IGF-1R, Akt/protein kinase, mTOR induce energy production in cancer cells and stimulate lipid and protein synthesis, which is responsible for a number of metabolic adaptations $[24,25]$. So inhibiting the IGF-1R pathway may induce significant changes in cancer cell metabolism and lead to retardation in proliferation, which is consist with our founding in this study.

p53, which was reported as tumor suppressor, has also an important role in the control of cell metabolism
[26]. Activation of p53 allows cells to respond to glucose deprivation by arresting their proliferation until glucose is restored. And it is conceivable that loss-offunction mutation of p53 in cancer cells may lead to stimulation of the glycolytic pathway [23]. Moreover, recent reports have revealed that $\mathrm{p} 53$ acts as a major energy conserving component following metformininduced AMPK activation [9, 10]. Tumor cells with loss of function of p53 are less able to compensate the metabolic stress induced by metformin and are more likely to undergo an energetic crisis because of their inability to stop proliferation [3], so p53-deficient cells showed an impaired ability to survive when treated with metformin compared with $\mathrm{p} 53^{+/+}$cells, which was highly in accordance with our data here.

As an upstream regulator of the IGF-1R gene, p53 effects converge on decreased IGF/IGF1R signaling by reducing both IGF bioavailability and IGF-1R density [27]. Cross-talk and coordination between the p53 and IGF-1R/Akt/TOR pathways have been proposed as means

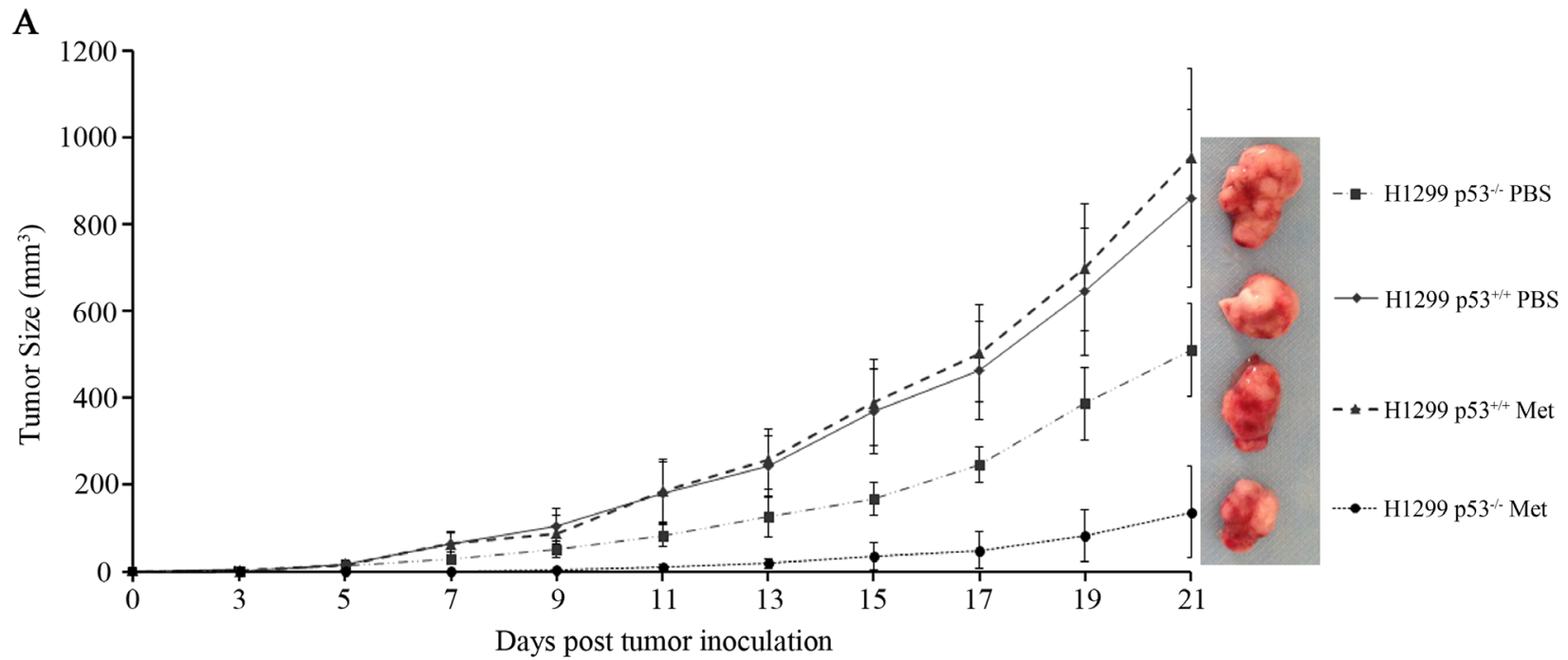

B

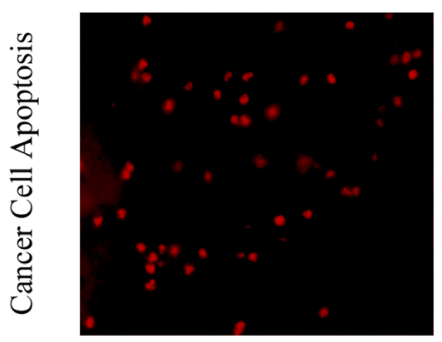

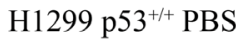

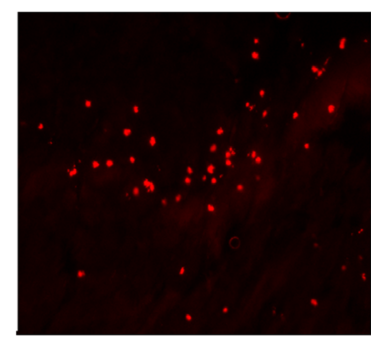

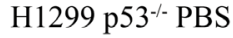

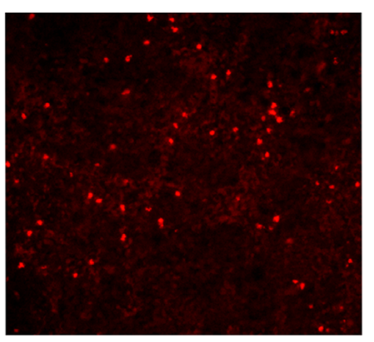

H1299 p53 $3^{+/+}$Met

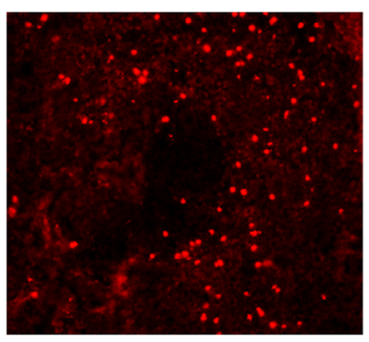

H1299 p53-/- Met

Figure 3: Difference in solid tumor growth retardation and cancer cell death induced by metformin in vivo. (A) After subcutaneous transplantation of $\mathrm{H} 1299$ cancer cells, the tumor growth in size was detected, tumor volume was calculated, and tumor growth curves were made. Solid tumors from all groups of mice were dissected and measured at the end of animal experiment. The results indicated statistical difference in tumor size between H1299 $\mathrm{p} 53^{+/+}$and H1299 $\mathrm{p} 53^{-/}$groups with metformin from day 7 (p $<0.05$, and p $<0.01$ from day 9). (B) Cell death caused by metformin in solid tumor sections were detected by TUNEL. We found more significant cancer cell death in p53-deficient cells (H1299 p53 ${ }^{-/}$) compare to p53 wild groups $(\mathrm{P}<0.05$, MOD for all groups were $0.046 \pm 0.0061,0.041 \pm 0.0073$, $0.137 \pm 0.0056,0.191 \pm 0.0047)$. 
A

IGF-1R

P53

GAPDH

B

H1299 p53 $3^{+/+}$
C

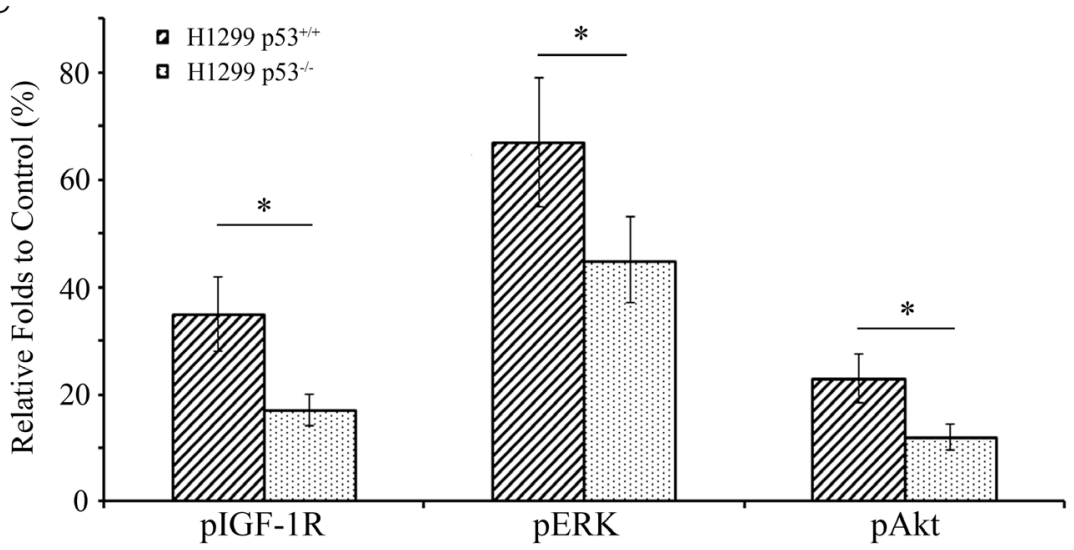

pIGF-1R

IGF-1R

pIGF-1R
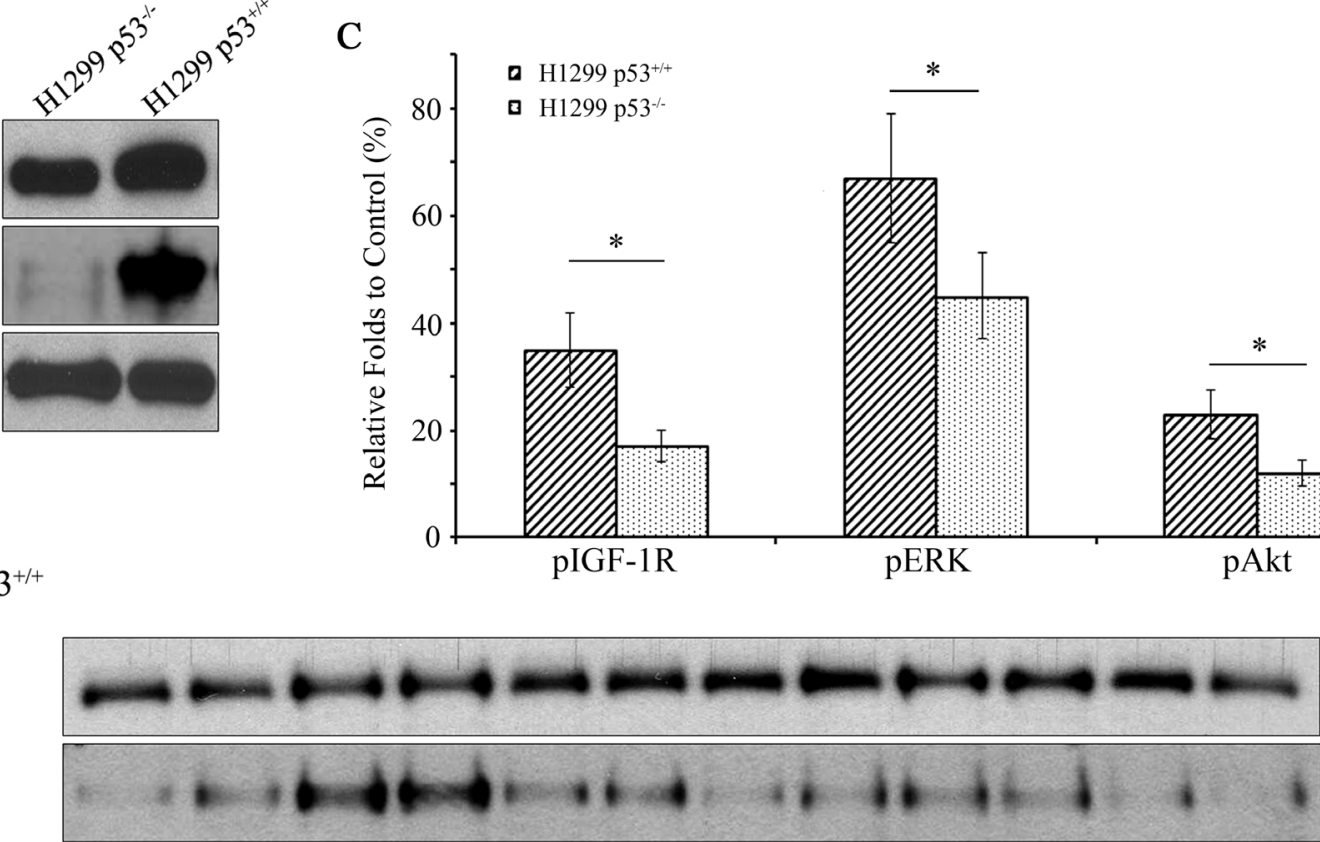

pERK

pAkt

GAPDH

Time (min)
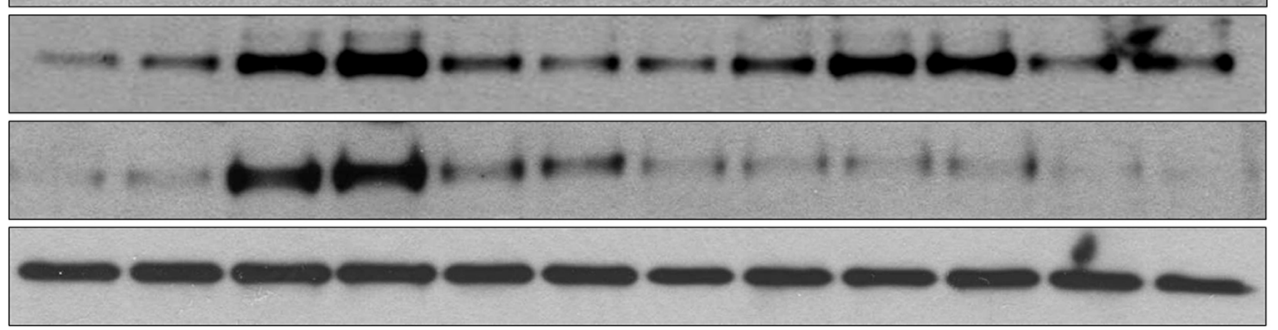

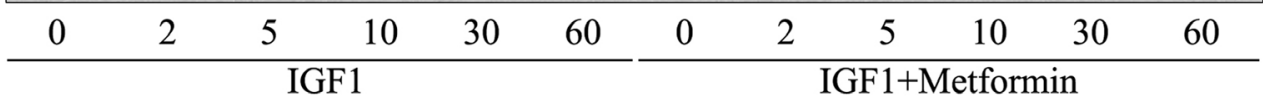

H1299 p53--

IGF-1R

pIGF-1R

pERK

pAkt

GAPDH

Time (min)

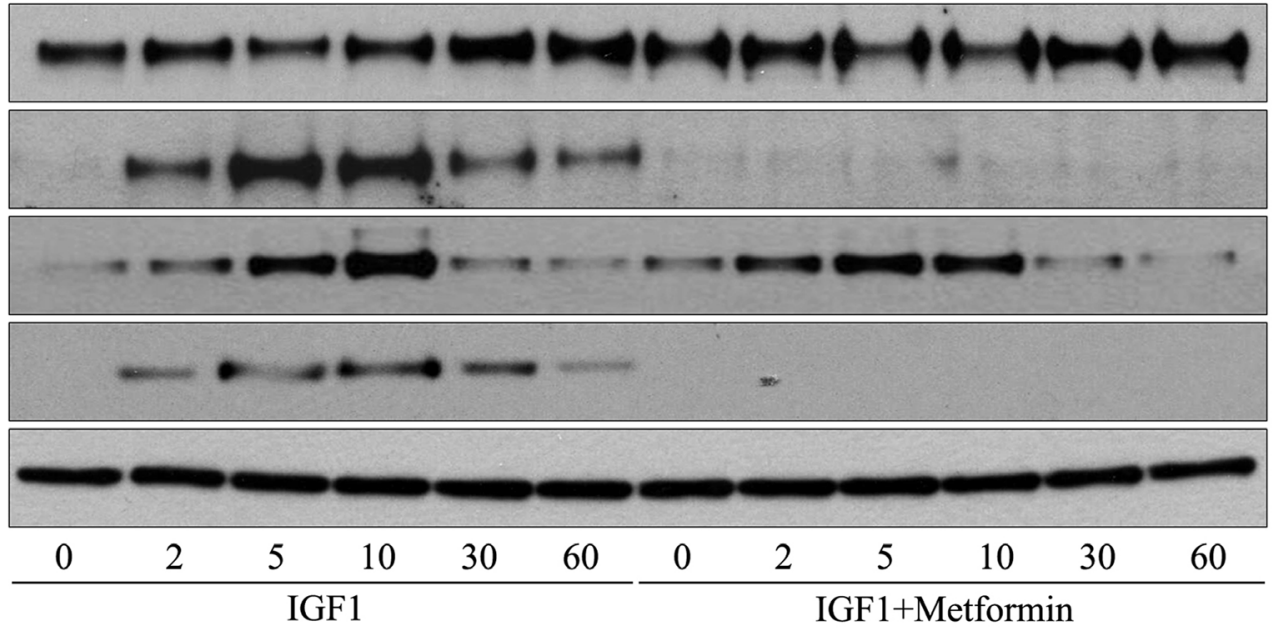

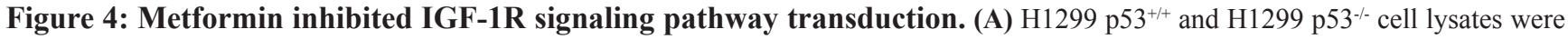
prepared and IGF-1R, p53 were detected by WB. (B) Cells were treated with $50 \mathrm{ng} / \mathrm{ml}$ IGF-1 or first treated with $3 \mathrm{mM}$ metformin for 30 min and then stimulated with $50 \mathrm{ng} / \mathrm{ml}$ IGF-1 for 2, 5, 10, 30 and $60 \mathrm{~min}$. Cell lysates were analyzed via WB for IGF-1R, pIGF-1R, pERK, pAKT and GAPDH on $0,2,5,10,30$ and 60 min. Metformin could significantly inhibit pIGF-1R, pERK amd pAKT activation in both $\mathrm{H} 1299 \mathrm{p} 53^{+/+}$and $\mathrm{H} 1299 \mathrm{p} 53^{-/}$cell lines. (C) Intensity of bands at different time points of cells with IGF 1+Metformin were quantified by densitometry, normalized to cells with IGF1 as control, and displayed as a percentage of the total intensity. Data were presented as mean

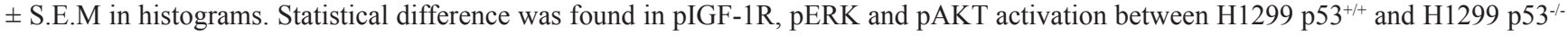
cancer cells $\left({ }^{*} \mathrm{P}<0.05\right)$. 
of integrating growth factor signaling, changes in nutrient levels and stress signals into regulation of cell growth, mitogenesis and apoptosis [28]. The IGF-1R signaling tends to be more malignant due to p53 deficiency, but seemed to be more susceptible to metformin treatment. Our data here indicated that more efficient retardation of IGF-1R signaling pathway and receptor degradation and ubiquitination were induced by metformin in the absent of p53 protein, resulting in enhanced proliferation inhibition, cell apoptosis in vitro and more significant solid tumor growth retardation and cancer cell death in vivo.

Although more cell lines and multiple animal experiments were required to make a general conclusion, our study suggested that the change in sensitivity of IGF-

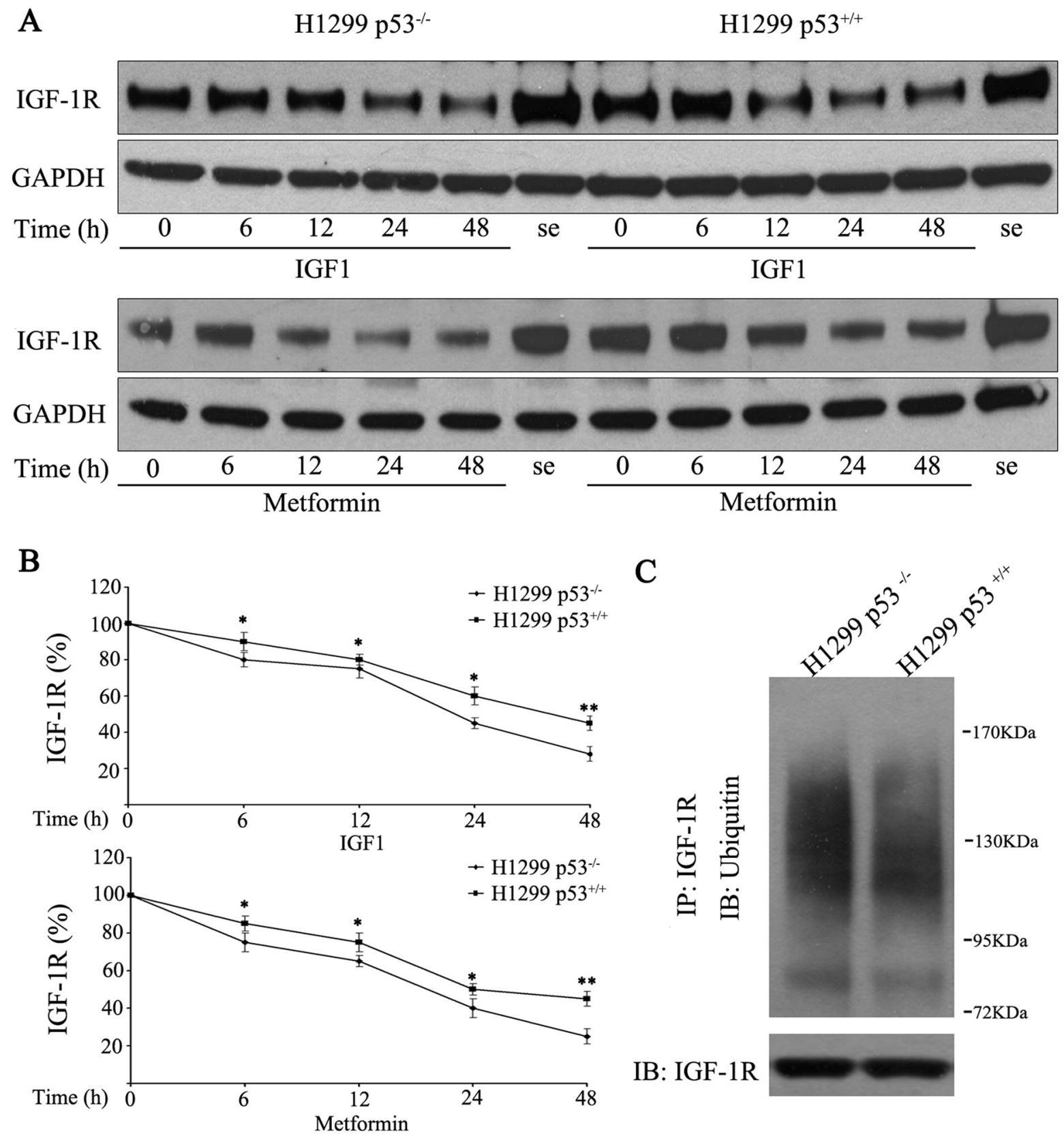

Figure 5: Metformin induced IGF-1R degradation and ubiquitination. (A) $50 \mathrm{ng} / \mathrm{ml} \mathrm{IGF}-1$ and $3 \mathrm{mM}$ Metformin was added to cells for a series of time points $(0,6,12,24,48 \mathrm{~h}$, serum as control). The expression level of IGF-1R and GAPDH were detected by WB. (B) Intensity of bands for IGF-1R at different time points were quantified by densitometry, normalized to GAPDH, data were presented as mean

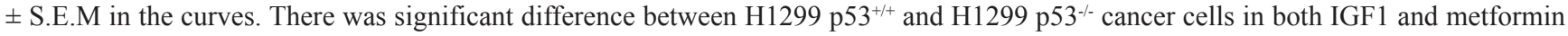
induced receptor degradation $\left({ }^{*} \mathrm{P}<0.05,{ }^{* *} \mathrm{P}<0.01\right)$. (C) Cells were simulated with $3 \mathrm{mM}$ metformin for 10 min after serum starvation for $24 \mathrm{~h}$. Cells were harvested with IP buffer. The IGF-1R antibody was used for immunoprecipitation, and immunobloting with ubiquitin antibody. Ubiquitination induced by metformin was significantly stronger in $\mathrm{H} 1299 \mathrm{p} 53^{-/}$cancer cells $(\mathrm{P}<0.05)$. 
1R signaling pathway to metformin may be the possible mechanism of metformin's selective toxicity in p53deficient cancer cells.

However, the clinical use of metformin as an antitumor agent is still awaited, although there were ongoing trails amassing evidence to ascertain if a survival benefits is associated with the use of metformin in various malignancies, the potential use of metformin as an immunotherapy agent needs to be substantiated with further evidence [29].

\section{MATERIALS AND METHODS}

\section{Reagents and cell culture}

Polyclonal antibodies against phosphorylated-AKT (S473), AKT, pERK1/2, ERK1/2, pIGF-1R and IGF-1R were purchased from Cell Signaling Technology (Danvers, MA, USA). Anti-p53 and GAPDH antibody was from Santa Cruz Biotechnology Inc (Santa Cruz, CA, USA). Metformin (150959-5G) was obtained from Sigma (St Louis, MO, USA).

The human non-small cell lung cancer A549, H460, H520 and H1975 cell lines were maintained in RPMI1640 supplemented with 10\% fetal bovin serum (FBS, Hyclone); H1299 (H1299 p53 $3^{-/-}$, P53 gene deletion) and H1299 p53 $3^{+/+}$(wild type P53 DNA transfected) cell lines were maintained in IMDM supplemented with 10\% FBS, 100 units $/ \mathrm{ml}$ penicillin and $100 \mu \mathrm{g} / \mathrm{ml}$ streptomycin was contained in all cell medium.

\section{Cell viability assay and flow cytometry}

Cells were cultured in 96 well plates overnight in the presence or absence of serum. Appropriate substrates were added to the wells for $12,24,48 \mathrm{~h}$, and then the cell viability was measured by PrestoBlue Cell Viability Assay (Invitrogen, CA, USA). Fluorescence was measured with excitation at $560 \mathrm{~nm}$ and emission at $590 \mathrm{~nm}$ wavelengths. Cell number was calculated from standard curve of fluorescence measurement.

For flow cytometry assay, cells were cultured in 6 well plates overnight and metformin was added to the wells for $24 \mathrm{~h}$. After that cells were collected in tubes and treated in accordance with Annexin V-FITC/PI apoptosis detection kit (Invitrogen, CA, USA). The cells apoptosis were imaged under a fluorescent microscope using 488 $\mathrm{nm}$ excitation, $515 \mathrm{~nm}$ emission for FITC and $560 \mathrm{~nm}$ emission for PI. Dead cells were labeled with Annexin V $(-)$ propidium iodide $(\mathrm{PI})(+)$ and are shown in the Q1 area; late apoptotic cells were labeled with Annexin V $(+)$ PI $(+)$ and are shown in the Q2 area; live cells were labeled with Annexin V (-) PI (-) and are shown in the Q3 area; early apoptotic cells were labeled with Annexin $\mathrm{V}(+) \mathrm{PI}(-)$ and are shown in the Q4 area (as shown in Figures 1C\&2B).

\section{SDS-PAGE and western blotting}

Protein samples were dissolved in LDS sample buffer (Invitrogen, CA, USA) containing $1 \mathrm{mM}$ $\beta$-mercaptoethnol, and analyzed by SDS-PAGE with $4-12 \%$ Bis-Tris gel (Invitrogen, CA, USA). After separation, the proteins were transferred to nitrocellulose membranes (GE Healthcare) at $4^{\circ} \mathrm{C}$ for 1 hour and then blocked for 1 hour at room temperature in a solution of $5 \%(\mathrm{w} / \mathrm{v})$ skimmed milk powder and $0.1 \%(\mathrm{w} / \mathrm{v})$ Tween 20 in Tris-buffered saline (TBS), pH 7.5 (TBS-T). After Incubated with appropriate primary antibodies overnight at $4{ }^{\circ} \mathrm{C}$, membranes were washed three times in TBS-T, and then incubated with a horseradish peroxidase-labeled secondary antibody (Pierce, IL, USA) for 1 hour at room temperature. The detection was made with ECL substrate (Pierce, IL, USA) and exposure to x-ray film.

\section{Real-time PCR and immunoprecipitation (IP)}

Total RNA of different cell lines was obtained using TRIzol reagent (Invitrogen), according to manufacturer's instructions. The RNA concentration was determined spectrophotometrically and intensity was detected by gel electrophoresis, and quality was confirmed in an Agilent 2100 Bioanalyzer (Agilent Technologies). The P53 mRNA was quantified by SYBR Green-quantitative real-time PCR and normalized to glyceraldehyde-3-phosphate dehydrogenase (GAPDH) as in our previous study [30]. The PCR primers used were as follows: P53 forward 5'-CCTCAGCATCTTATCCGAGTGG-3' and reverse 5'-TGGATGGTGGTACAGTCAGAGC-3', GAPDH forward 5'-TGACCACATCCTATGCCACT-3' and reverse 5'-CCACCTTCTTGCTGTAGCT-3'.

Cells were lysed with IP lysis buffer supplied by Invitrogen, using $500 \mu \mathrm{l}$ lysis buffer with $10 \mathrm{mM}$ $\mathrm{N}$-ethylmaleimide, $50 \mu \mathrm{M}$ MG132, and protease inhibitor cocktail tablet (Roche) per well in the 6-well plates. After incubated with $1 \mathrm{mg}$ antibody for $3 \mathrm{~h}$ at $4^{\circ} \mathrm{C}$, the samples were added with $15 \mu$ l Dynabeads Protein G (Invitrogen, CA, USA), and incubated on a rocker platform at $4^{\circ} \mathrm{C}$ overnight. Then the immunoprecipitated complexes were collected by magnet, the supernatant discarded, and the beads were washed three times with lysis buffer and dissolved in sample buffer for western blot.

\section{Solid tumor formation and TUNEL}

BALB/c-nu mice (female, 5-6 weeks old) were purchased from vital River Laboratory Animal Technology (Beijing, China) and maintained under specific pathogenfree conditions. H1299 p53 $3^{+/+}$and p53/- cells $\left(4 \times 10^{6}\right)$ were subcutaneously injected. Tumor sizes were measured by longitudinal $(L)$ and transverse $(W)$ diameters every other day and tumor volumes were calculated as $V=L \times W^{2} / 2$ [31]. The endpoint for this study was set to be three weeks after tumor cells administration, and then all mice were 
sacrificed under anesthesia and tumors were exercised and weighed. Tissue samples were embedded in paraffin wax and serially sectioned. All animal experimental protocols were approved by the Ethics Committee of Shandong University.

Tumor sections were deparaffinized and rehydrated, incubated with protease $\mathrm{K}$ for $25 \mathrm{~min}$ at room temperature for antigen retrieval, and then operated according to the protocol of the TUNEL apoptosis detection kit (Zhong shan jin qiao, China). The red-labeled TUNEL positive cells were imaged under a fluorescent microscope using $488 \mathrm{~nm}$ excitation and $530 \mathrm{~nm}$ emission. An image analyser (Media Cybernetics) was used to score the staining sections of TUNEL, and results were present in mean optical density (MOD = integrated optical density/ area) as in our previous study [32].

\section{Statistical analysis}

All experiments were repeated at least three times and the values were expressed as the mean \pm standard error. Statistical significance was determined by Student's t-test using SPSS 17.0 statistical software (SPSS Inc, Chicago, IL). For all tests, a $p$ value less than 0.05 was considered to be statistically significant.

\section{CONFLICTS OF INTEREST}

The authors declare that they have no conflicts of interest.

\section{GRANT SUPPORT}

The authors have received support from Provincial Medical Science and Technology Development Planning of Shandong (2014WS0342) and Shandong Provincial Natural Science Fund (ZR2014HQ073) and Key Research Project Funding of Shandong Province (2015GSF118109).

\section{REFERENCES}

1. Kourelis TV, Siegel RD. Metformin and cancer: new applications for an old drug. Med Oncol. 2012; 29: 131427. https://doi.org/10.1007/s12032-011-9846-7.

2. Kato H, Sekine Y, Furuya Y, Miyazawa Y, Koike H, Suzuki K. Metformin inhibits the proliferation of human prostate cancer PC-3 cells via the downregulation of insulin-like growth factor 1 receptor. Biochem Biophys Res Commun. 2015; 461: 115-21. https://doi.org/10.1016/j. bbrc.2015.03.178.

3. Daugan M, Dufay Wojcicki A, d'Hayer B, Boudy V. Metformin: an anti-diabetic drug to fight cancer. Pharmacol Res. 2016; 113: 675-85. https://doi.org/ S1043-6618(16)30368-1.

4. Smardova J, Liskova K, Ravcukova B, Malcikova J, Hausnerova J, Svitakova M, Hrabalkova R, Zlamalikova L,
Stano-Kozubik K, Blahakova I, Speldova J, Jarkovsky J, Smarda J. Complex analysis of the p53 tumor suppressor in lung carcinoma. Oncol Rep. 2016; 35: 1859-67. https://doi. org/10.3892/or.2015.4533.

5. Bian C, Li Z, Xu Y, Wang J, Xu L, Shen H. Clinical outcome and expression of mutant P53, P16, and Smad4 in lung adenocarcinoma: a prospective study. World J Surg Oncol. 2015; 13: 128. https://doi.org/10.1186/s12957-015-0502-0.

6. Levine AJ, Momand J, Finlay CA. The p53 tumour suppressor gene. Nature. 1991; 351: 453-6. https://doi. org/10.1038/351453a0.

7. Melino G. Journal club. A cancer biologist weighs up p53, metabolism and cancer. Nature. 2010; 466: 905. https://doi. org/10.1038/466905d.

8. Cairns RA, Harris IS, Mak TW. Regulation of cancer cell metabolism. Nat Rev Cancer. 2011; 11: 85-95. https://doi. org/10.1038/nrc2981.

9. Pollak M. Potential applications for biguanides in oncology. J Clin Invest. 2013; 123: 3693-700. https://doi.org/10.1172/ JCI67232.

10. Buzzai M, Jones RG, Amaravadi RK, Lum JJ, DeBerardinis RJ, Zhao F, Viollet B, Thompson CB. Systemic treatment with the antidiabetic drug metformin selectively impairs p53-deficient tumor cell growth. Cancer Res. 2007; 67: 6745-52. https://doi.org/67/14/6745.

11. Li P, Zhao M, Parris AB, Feng X, Yang X. p53 is required for metformin-induced growth inhibition, senescence and apoptosis in breast cancer cells. Biochem Biophys Res Commun. 2015; 464: 1267-74. https://doi.org/10.1016/j. bbrc.2015.07.117.

12. Estan MC, Calvino E, de Blas E, Boyano-Adanez Mdel C, Mena ML, Gomez-Gomez M, Rial E, Aller P. 2-Deoxy-Dglucose cooperates with arsenic trioxide to induce apoptosis in leukemia cells: involvement of IGF-1R-regulated Akt/ mTOR, MEK/ERK and LKB-1/AMPK signaling pathways. Biochem Pharmacol. 2012; 84: 1604-16. https://doi. org/10.1016/j.bcp.2012.09.022.

13. Zheng H, Shen H, Oprea I, Worrall C, Stefanescu R, Girnita A, Girnita L. beta-Arrestin-biased agonism as the central mechanism of action for insulin-like growth factor 1 receptor-targeting antibodies in Ewing's sarcoma. Proc Natl Acad Sci U S A. 2012; 109: 20620-5. https://doi. org/10.1073/pnas.1216348110.

14. Min HY, Yun HJ, Lee JS, Lee HJ, Cho J, Jang HJ, Park $\mathrm{SH}$, Liu D, Oh SH, Lee JJ, Wistuba II, Lee HY. Targeting the insulin-like growth factor receptor and Src signaling network for the treatment of non-small cell lung cancer. Mol Cancer. 2015; 14: 113. https://doi.org/10.1186/ s12943-015-0392-3.

15. Cao H, Dong W, Qu X, Shen H, Xu J, Zhu L, Liu Q, Du J. Metformin enhances the therapy effects of anti-IGF-1R mAb figitumumab to NSCLC. Sci Rep. 2016; 6: 31072. https://doi.org/10.1038/srep31072.

16. Cao H, Dong W, Shen H, Xu J, Zhu L, Liu Q, Du J. Combinational therapy enhances the effects of anti-IGF-1R 
$\mathrm{mAb}$ figitumumab to target small cell lung cancer. PLoS One. 2015; 10: e0135844. https://doi.org/10.1371/journal. pone. 0135844 .

17. Xie Y, Wang JL, Ji M, Yuan ZF, Peng Z, Zhang Y, Wen JG, Shi HR. Regulation of insulin-like growth factor signaling by metformin in endometrial cancer cells. Oncol Lett. 2014; 8: 1993-9. https://doi.org/10.3892/ol.2014.2466.

18. Bhaw-Luximon A, Jhurry D. Metformin in pancreatic cancer treatment: from clinical trials through basic research to biomarker quantification. J Cancer Res Clin Oncol. 2016; 142: 2159-71. https://doi.org/10.1007/s00432-016-2178-4.

19. Mitsiades CS, Mitsiades NS, McMullan CJ, Poulaki V, Shringarpure R, Akiyama M, Hideshima T, Chauhan D, Joseph M, Libermann TA, Garcia-Echeverria C, Pearson MA, Hofmann F, et al. Inhibition of the insulin-like growth factor receptor-1 tyrosine kinase activity as a therapeutic strategy for multiple myeloma, other hematologic malignancies, and solid tumors. Cancer Cell. 2004; 5: 22130. https://doi.org/S1535610804000509.

20. Werner H. For debate: the pathophysiological significance of IGF-I receptor overexpression: new insights. Pediatr Endocrinol Rev. 2009; 7: 2-5.

21. Shen H, Fang Y, Dong W, Mu X, Liu Q, Du J. IGF-1 receptor is down-regulated by sunitinib induces MDM2dependent ubiquitination. FEBS Open Bio. 2012; 2: 1-5. https://doi.org/10.1016/j.fob.2011.12.001.

22. Attias-Geva Z, Bentov I, Ludwig DL, Fishman A, Bruchim I, Werner H. Insulin-like growth factor-I receptor (IGF-IR) targeting with monoclonal antibody cixutumumab (IMCA12) inhibits IGF-I action in endometrial cancer cells. Eur J Cancer. 2011; 47: 1717-26. https://doi.org/10.1016/j. ejca.2011.02.019.

23. Werner H. Tumor suppressors govern insulin-like growth factor signaling pathways: implications in metabolism and cancer. Oncogene. 2012; 31: 2703-14. https://doi. org/10.1038/onc.2011.447.

24. Plas DR, Thompson CB. Akt-dependent transformation: there is more to growth than just surviving. Oncogene. 2005; 24: 7435-42. https://doi.org/1209097.
25. Guertin DA, Sabatini DM. Defining the role of mTOR in cancer. Cancer Cell. 2007; 12: 9-22. https://doi.org/ S1535-6108(07)00151-1.

26. Sen N, Satija YK, Das S. p53 and metabolism: old player in a new game. Transcription. 2012; 3: 119-23. https://doi. org/10.4161/trns.20094.

27. Grimberg A, Coleman CM, Shi Z, Burns TF, MacLachlan TK, Wang W, El-Deiry WS. Insulin-like growth factor factor binding protein-2 is a novel mediator of p53 inhibition of insulin-like growth factor signaling. Cancer Biol Ther. 2006; 5: 1408-14. https://doi.org/3455.

28. Levine AJ, Feng Z, Mak TW, You H, Jin S. Coordination and communication between the p53 and IGF-1-AKT-TOR signal transduction pathways. Genes Dev. 2006; 20: 267-75. https://doi.org/20/3/267.

29. Chae YK, Arya A, Malecek MK, Shin DS, Carneiro B, Chandra S, Kaplan J, Kalyan A, Altman JK, Platanias L, Giles F. Repurposing metformin for cancer treatment: current clinical studies. Oncotarget. 2016; 7: 40767-80. https://doi.org/10.18632/oncotarget.8194.

30. Ni Y, Wang L, Zhang J, Pang Z, Liu Q, Du J. PKD1 is downregulated in non-small cell lung cancer and mediates the feedback inhibition of mTORC1-S6K1 axis in response to phorbol ester. Int J Biochem Cell Biol. 2015; 60: 34-42. https://doi.org/10.1016/j.biocel.2014.12.018.

31. Dong W, Qiu C, Shen H, Liu Q, Du J. Antitumor effect of embryonic stem cells in a non-small cell lung cancer model: antitumor factors and immune responses. Int J Med Sci. 2013; 10: 1314-20. https://doi.org/10.7150/ijms.6538.

32. Dong W, Du J, Shen H, Gao D, Li Z, Wang G, Mu X, Liu Q. Administration of embryonic stem cells generates effective antitumor immunity in mice with minor and heavy tumor load. Cancer Immunol Immunother. 2010; 59: 1697-705. https://doi.org/10.1007/s00262-010-0899-9. 